\title{
GCU
}

Glasgow Caledonian

University

University for the Common Good

\section{Preparing registrants for mentor roles: the chicken or egg conundrum}

McGuinness, C.; McCallum, J.; Duffy, K.

Published in:

Nursing Management

DOI:

$10.7748 / \mathrm{nm} .2016 . \mathrm{e} 1524$

Publication date:

2016

Document Version

Author accepted manuscript

Link to publication in ResearchOnline

Citation for published version (Harvard):

McGuinness, C, McCallum, J \& Duffy, K 2016, 'Preparing registrants for mentor roles: the chicken or egg conundrum', Nursing Management, vol. 23, no. 8, pp. 36-39. https://doi.org/10.7748/nm.2016.e1524

\section{General rights}

Copyright and moral rights for the publications made accessible in the public portal are retained by the authors and/or other copyright owners and it is a condition of accessing publications that users recognise and abide by the legal requirements associated with these rights.

Take down policy

If you believe that this document breaches copyright please view our takedown policy at https://edshare.gcu.ac.uk/id/eprint/5179 for details of how to contact us. 
Nursing Management

Evidence and practice/?

Preparing registrants for mentor roles: the chicken or egg conundrum

McGuinness C, McCallum J, Duffy K (2016) Preparing registrants for mentor roles: the chicken or egg conundrum. Nursing Management. Date of submission:; date of acceptance:.doi:

Claire McGuinness

Lecturer/Acting Mentorship Coordinator, Health and Community Sciences, Glasgow Caledonian University, Glasgow

Jacqueline McCallum

Assistant Head of Department, Health and Community Sciences, Glasgow Caledonian University Kathleen Duffy

Senior nurse practice education, NHS Lanarkshire

Correspondence

claire.mcguinness@gcu.ac.uk

Review

This article has been subject to double-blind review and has been checked for plagiarism using automated software

Conflict of interest

There is no conflict of interest.

Abstract

The Nursing and Midwifery Councils (NMC) standards to support learning and assessment in practice (2008) outline requirements for the preparation of those who support nursing and midwifery preregistration students in practice, formally known as mentors. Pre-registration nursing and midwifery programme providers and practice learning environments (PLEs) work collaboratively to prepare registrants to undertake this role, and to assist them to maintain mentor status. An important NMC requirement is that registrants, when undertaking mentor preparation programmes, must be supported by experienced mentors from within their workplace. This is challenging for both programme providers and PLEs if there is lack of experienced mentors in the area concerned. This article discusses support for registrants when preparing to become mentors, suggests some alternative solutions, and makes recommendations for the future of mentor preparation in the UK. Mentorship preparation, mentor, sign-off mentor, teacher 


\section{Introduction}

The debate on the preparation of mentors and the delivery of mentorship in the UK is fluid and ongoing (King's College London 2012). The Royal College of Nursing (RCN) commissioned a review of mentoring models, internationally and across a variety of professions, to support development of recommendations for mentorship practice and student support (2015a). Important findings from the report include recognition of the importance of mentorship, and the need to continue to invest in the development of mentors and the provision of this support for learners (RCN 2015a). In light of this, the RCN (2015b) committed to 'support and promote new models of mentorship', which is of particular importance when considering how best to continue to develop effective mentors in the UK.

The Nursing and Midwifery Council (NMC) Standards to Support Learning and Assessment in Practice (SLAiP) (2008) outline the regulatory requirements for the development of mentorship preparation programmes in the UK, and maintenance of mentorship status, and NHS Education for Scotland (NES) (2013) provides further detailed curriculum guidance for their development in Scotland.

The term 'mentor' denotes a registrant who has successfully completed an NMC-approved mentorship preparation programme, which allows them to support and assess pre-registration students in practice (NMC 2008). 'Student mentor' refers to a registrant who is undertaking mentorship preparation. During this time, which is normally three months, registrants must be supervised by experienced mentors. The term 'sign-off' mentor (NMC 2008, 2010a) describes a mentor who, following a period of supervision by an experienced sign-off mentor, can support and assess final placement pre-registration students without supervision. Following attainment of mentor/sign-off mentor status, registrants are annotated to a mentor register and can support nursing students unsupervised.

Although the NMC (2008) refers to the role of experienced mentors in mentor preparation, NES (2013) provides definitive guidance. Referring to these experienced mentors as 'supervising mentors', which is the term adopted in this article, NES (2013) delineates specific responsibilities in terms of the role and its contribution to student mentor support. This is now widely recognised in Scotland as a defined role in terms of preparing registrants to become mentors.

Despite this guidance, little steer is given in relation to the initiation of new practice learning environments (PLEs) in areas where there are no mentors. This means that areas which do not have 
mentors find it particularly difficult to become established as a practice learning area due to the absence of mentors to take on the role of supervising mentor.

The challenge, therefore, is how to help these areas prepare new mentors in the absence of experienced ones, as adherence to the NMC mentoring standards (2008) effectively precludes this. Many higher education institutions (HEIs) want to increase the number of PLEs available to nursing students, but find it difficult to achieve this mainly because of this problem. Consequently, areas that could provide educationally relevant placements are untapped because of the absence of supervising mentors. In addition, non-NHS environments, including care homes and hospices, often experience increased difficulty in preparing mentors, because they are not part of a large organisation and usually work in isolation as discrete organisations and often have fewer registrants than NHS practice areas. This latter point usually means that non-NHS organisations find it challenging to release registered staff to attend mentorship preparation.

The absence of supervising mentors in some PLEs means they cannot fulfil the requirements of SLAiP (NMC 2008), and therefore cannot prepare new mentors. This also prevents them from engaging with and supporting nursing students, which is valuable experience for practice placements, and can limit registrants' ability to fulfil some requirements of the NMC Code (2015a; p9), specifically to 'support students' and colleagues' learning, to help them develop their professional competence and confidence.'

There are additional challenges in relation to sign-off mentors. The NMC (2010a) states that in the final PLE pre-registration nursing students must be supervised by a sign-off mentor. They are responsible for making the final decision about whether students have achieved the standards of proficiency for safe and effective practice required for entry to the register (NMC 2008). However, if PLEs do not have sign-off mentors, existing mentors cannot gain sign-off mentor status. NMC recognised this problem, and released a circular (NMC 2010b) which outlined some acceptable adaptations for sign-off mentor preparation; these included simulation, role play and other teaching and learning strategies. However, the final sign-off experience must take place with a real student during the last PLE and this still requires a supervising sign-off mentor who is annotated to the live mentor register. Unfortunately, HEl lecturers, who are often no longer annotated this register as they do not regularly mentor students in practice, fail to meet the NMC requirements (2008), and 
cannot therefore provide sign-off mentor preparation support. It is this conundrum which underpins the following discussion.

\section{Lecturer not mentor}

NMC consider SLAiP (2008; p12) as a developmental framework when they state that 'There is a single developmental framework to support learning and assessment in practice.' The framework is supported by five principles, and comprises of eight domains which have identified outcomes for the four developmental stages. These are; registrant, mentor, practice teacher and lecturer (Figure 1).

Figure 1: The four stages and eight domains of the Nursing and Midwifery Council mentorship developmental framework (2008)

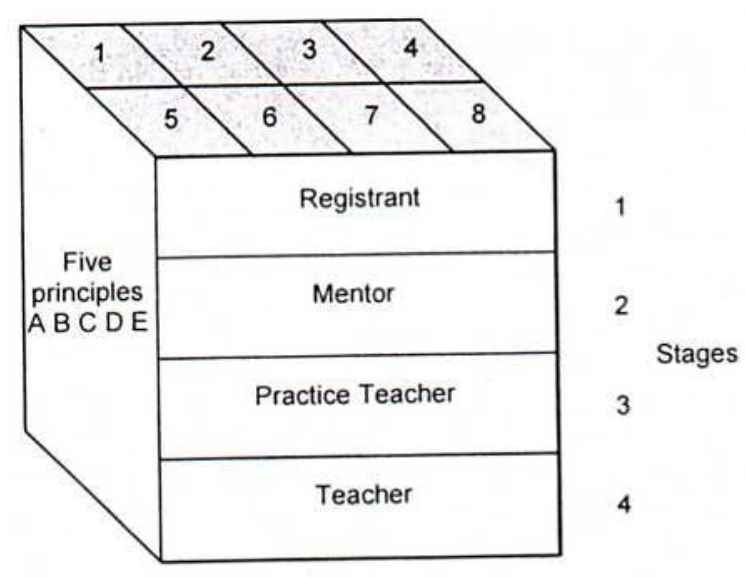

Reproduced and reprinted with permission from the Nursing and Midwifery Council (2008)

The eight domains are:

1. Establishing effective working relationships.

2. Facilitation of learning.

3. Assessment and accountability.

4. Evaluation of learning.

5. Creating an environment for learning.

6. Context of practice.

7. Evidence-based practice.

8. Leadership. 
The word 'developmental', used as a framework descriptor, suggests skill progression through stages one to four however, if this is the case, then why can university teachers not adopt the role of supervising mentors should one of the circumstances described previously arise? Perhaps considering some definitions of development might clarify the issue. Development is defined, by the Cambridge dictionary (2014), as 'the process through which someone or something grows or changes and becomes more advanced', or 'the process of developing something new'. NMC appears to have aligned with the latter definition, as it indicates that 'it is possible to enter and exit the framework at any stage; this means that no one stage is a pre-requisite for a subsequent stage' (2008). However, it could be argued that the former definition is more pertinent, as the criteria for nurses who intend to undertake the role of teacher (NMC 2008) includes a prerequisite to 'able to teach and assess in both practice and academic settings' (NMC 2008; p33). This suggests that mentorship skills are a precondition to becoming a teacher of nursing.

It seems logical to assume that undertaking a teacher qualification, and practising in that role, enhances the growth of individuals' teaching and assessment skills; integral components of mentorship. Despite this, NMC's (2008; p28) stance is sometimes contradictory, exemplified by the following statement: 'Only teachers who work in both practice and academic settings, for example lecturer practitioners, may assess practice', and '(a teacher must) act as a practice expert to support development of knowledge and skills for practice'. The latter statement supports the argument that teachers/university lecturers continue to use mentorship skills in academic settings, mirroring, at an advanced level, the work of mentors, most notably in clinical simulation environments. This maintenance, diversification, and enhancement of mentorship skills, although in a different context, raises the question why are these professionals are regarded as unsuitable to adopt the role of supervising mentors. Further strengthening this case, NMC (2010a) recognise the role and context of clinical simulation in terms of practice experience and skill development when stipulating that a maximum of 300 clinical simulation hours can contribute to the required practice hours of preregistration nursing programmes.

The debate about link lecturer (teacher) roles is also resurfacing, with a call to strengthen the roles in mentorship (Foster et al 2015). Although there are inconsistencies in how these roles are enacted in PLEs across the UK and beyond (Maclntosh 2015), one aspect identified by Collington et al (2012) is participation in practice-based assessments. Practice-based assessment of pre-registration nursing 
students is an important part of mentors' and sign-off mentors' roles. If link lecturers participate in students practice assessments, this further supports the view that lecturers maintain important aspects of their mentorship skills, adding weight to the argument that they should be regarded as suitable to act as supervising mentors for student mentors. Once again however it does appear that NMC (2008; p29) recognise this, as seen in the following statement: '(teachers must) act as a role model to enable students to learn professional responsibilities and how to be accountable for their own practice.' It seems particularly incongruent, therefore, that lecturers are regarded as fit to teach theoretical aspects of teaching, learning and assessment to student mentors, but cannot support and assess them in practice.

One of the main barriers to teachers undertaking supervising mentor roles appears to be the way in which NMC defines mentors, stating that they must be annotated to the mentor register, and to remain so, must mentor a minimum of two students during a three-year period. At present, most teachers are not annotated to local mentor registers, and are not therefore recognised as able to undertake supervising mentor roles.

NMC are currently refreshing SLAiP (NMC 2008), therefore it is perhaps time to reconsider the requirements and the terminology. This partly aligns with RCN's (2015b) recommendation that the use of role classification in mentorship should be explored. For example, it might be better to replace references to 'experienced mentor' with 'practitioners at stage 2,3 , or $4 . .$. ' according to their experience of teaching and learning within the developmental framework (NMC 2008). It may also be useful to reconsider the guidance on annotation to the mentor register. As previously highlighted, the term developmental indicates increasing skill and expertise; recognised by NMC's acceptance that teachers demonstrate capability in their role by practicing across practice and academic settings when supporting students. Teachers 'expertise is therefore enhanced by their involvement and contribution as a link lecturer in the practice assessment of students.

The Shape of Caring Review (Lord Willis 2015), commissioned by Health Education England in partnership with the NMC, makes 34 recommendations for the future of nursing education. Many of these recommendations are designed to assure high-quality learning environments for preregistration students, central to which is the ethos of partnership working between HEls and PLE providers. Enabling teachers to undertake supervising mentor roles for student mentors could 
strengthen partnerships in PLEs across the UK, and start to address the inconsistencies in link lecturer roles in practice. The need to strengthen academic-practice links is illustrated by the NMC (2015) Quality Assurance Framework, which stipulates the requirement for cohesive partnership working across academic and practice settings, to quality assure PLEs and students' experiences.

In summary, this article proposes that teachers meet the requirements for mentor status, an argument that is reinforced by a review of NMC (2008) SLAiP and the developmental framework learning outcomes. Those who engage with this development increase their knowledge, skills and their application to practice when supporting practice learning. Therefore, it could be argued that involving teachers in supporting student mentors should be explored and implemented as part of a permanent solution to the conundrum of establishing mentors in areas where there are no existing experienced mentors to take on the role of supervising mentor.

\section{Recommendations}

It would therefore perhaps be prudent, and educationally sound, to support lecturers to adopt the role of supervising mentor in areas where there is a desire to initiate mentor support and student practice learning experiences. This could offer some benefits should the NMC, as part of SLAiP (NMC 2008) refresh, reconsider the effects of the developmental framework, and the opportunities it offers for a more integrated nursing and midwifery practice learning infrastructure, in particular recognition of the transferable nature of teaching and assessment skills which increase in complexity as registrants progress through the stages of development to teacher. Similarly, the terminology associated with mentorship and mentorship support requires review to allow it more accurately reflect the transitional nature of engagement with the developmental framework (NMC 2008).

Finally, visual representation of the developmental framework illustrated the developmental framework as discrete development entities, rather than the transitional development advocated by NMC (2008). It may be more appropriate therefore to use an inverted pyramid representation, which is more indicative of the widening range of skills that increase in complexity alongside the knowledge that stems from developmental progression (Figure 2). 


\section{Stage 4 - Teacher}

...an NMC registrant who, following succesful completion of an NMC approved teacher preparation programme, has achieved the knowledge, skills and competence required to meet NMC defined outcomes of stage 4 of the developmental framework: (NMC 2008, p32)
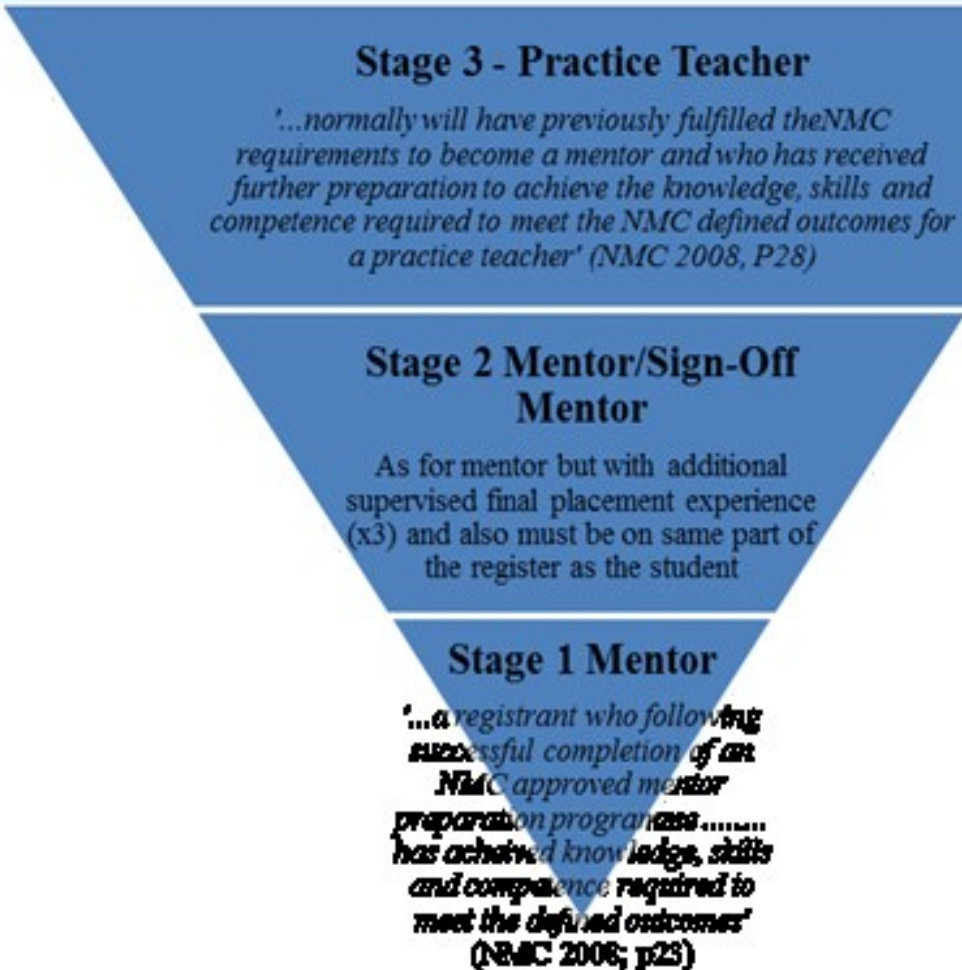

Figure 2: Inverted pyramid developmental framework representation

\section{Conclusion}

It is evident, from a review of SLAiP (NMC 2008), that the developmental framework is as it states; developmental. The skills, attributes and knowledge required to mentor effectively, increase in complexity as registrants' progress towards practice teacher and teacher status. However, it is important to recognise the intrinsic links which span this framework; the requirements for each stage of the framework are inherently similar, despite increasing in complexity. Further, there would appear to be a tacit acceptance that those who progress through the framework have developed the preceding skills, in keeping with the ethos of development. This perhaps raises more questions about the rationale for excluding teachers from involvement in preparing student mentors, particularly when considering the in-depth knowledge these professionals require to enable them to teach across a variety situations, environments and students (both undergraduate and post-graduate. This, added to the fact that teachers can prepare other professionals to educate 
nursing and midwifery students, compounds the argument for teachers' roles in preparing and supporting student mentors in practice settings.

NMC (2008) perhaps explicate their stance when citing familiarity and involvement in practice as a pre-requisite if planning to be involved in student practice learning assessment. It could be argued however, that it is an inherent part of teachers' responsibilities to maintain their professional practice in terms of both currency and authenticity, in all aspects of their role. This can be achieved through academic endeavour or through engagement with practice on a more practical level. Either way, and in view of the changes to NMC revalidation (2015b), teachers' obligations are clear and, it could be argued, lend themselves to the preparation of mentors in the practice setting as well as the academic arena. This is further emphasised when considering the curriculum of mentorship preparation which focuses on the teaching and assessing role rather than educating student mentors about clinical priorities in their own areas. This reflects the expectation that those undertaking mentorship preparation will be supported to learn to mentor rather than be supported to deliver care; emphasising the educational focus of the supervising mentor role. This is an important factor which must form part of this debate, and should be considered as part of the refresh of SLAiP (NMC 2008).

\section{References}

Cambridge University Press (2014), Cambridge Advanced Learner's Dictionary. 14th edition. Cambridge University Press, London.

Collington V, Mallik M, Doris F Fraser D, 2012. 'Supporting the midwifery practice-based curriculum: the role of the link lecturer'. Nurse Education Today. 32, 8, p924-929.

Foster H, Ooms A, Marks-Maran D, 2015. 'Nursing students' expectations and experiences of mentorship'. Nurse Education Today. 35, 3, p18-24. 
Kings College London, 2012. Sustaining and managing the delivery of student nurse mentorship: Roles, resources, standards and debates. Available at https://www.kcl.ac.uk/nursing/research/nnru/publications/Reports/Nurse-Mentorship-ReportNov2012.pdf [online]. Accessed $5^{\text {th }}$ May 2016

Lord Willis. 2015. Raising the bar: Shape of caring: A review of the future education and training of registrants and care assistants. Health Education England. Available at: http://hee.nhs.uk/wpcontent/blogs.dir/321/files/2015/03/2348-Shape-of-caring-review-FINAL.pdf [online]. Accessed $24^{\text {th }}$ October 2016

MacIntosh T, 2015. 'The link lecturer role; inconsistent and incongruent realities.' Nurse Education Today. 35, 3, p8-13.

NHS Education for Scotland, 2013.National Approach to Mentor Preparation for Nurses and Midwives: Core Curriculum Framework, 2nd Edition. NES: Edinburgh.

Nursing \& Midwifery Council. 2008. Standards to support learning and assessment in practice. London, NMC.

Nursing \& Midwifery Council. 2010a. Standards for pre-registration nursing education. London, NMC.

Nursing \& Midwifery Council. 2010b. Circular 05/2010 Sign-off mentor criteria. London, NMC.

Nursing \& Midwifery Council, 2015. Quality Assurance Framework. Available at:

http://www.nmc.org.uk/globalassets/siteDocuments/EdandQA/Quality-assurance-framework.pdf [online]. Accessed 25th October 2016 
Nursing \& Midwifery Council, 2015. The Code. Available at:

http://www.nmc.org.uk/standards/code/read-the-code-online/ [online]. Accessed: 24th October 2016

Royal College of Nursing, 2015a. RCN Mentorship Project 2015: From Today's Support in Practice to Tomorrow's Vision for Excellence - Rapid Evidence Review. RCN, London

Royal College of Nursing, 2015b. RCN Mentorship Project 2015: From Today's Support in Practice to Tomorrow's Vision for Excellence - Project Report. RCN, London 